\section{International Journal of Medical \\ Research and Review}

2019 Volume 7 Number 6 November-December
MEDRESEARCH

www.medresearch.in

\title{
Spinal anesthesia during cesarean section and persisting low back pain: a cross sectional study in West Bengal, India
}

\author{
Mukhopadhyay A. ${ }^{1}$, Bhattacharyya A. ${ }^{2}$, Chanda $5^{3{ }^{*}}{ }^{\text {, Kumar Syamal A. }}{ }^{4}$ \\ DOI: https://doi.org/10.17511/ijmrr.2019.i06.09 \\ ${ }^{\mathbf{1}}$ Aditi Mukhopadhyay, Post Graduate, Department of Physiology, Hooghly Mohsin College, University of Burdwan, Bardhaman, West Bengal, \\ India. \\ 2 Arpan Bhattacharyya, Post Graduate, Department of Physiology, Hooghly Mohsin College, University of Burdwan, Bardhaman, West \\ Bengal, India. \\ 3* Sarmishtha Chanda, Department of Physiology, Sister Nibedita Govt. General Degree College for Girls, Hastings House, Kolkata, West \\ Bengal, India. \\ ${ }^{4}$ Alak Kumar Syamal, Post Graduate, Department of Physiology, Hooghly Mohsin College, University of Burdwan, Bardhaman, West Bengal, \\ India.
}

Background: Spinal anesthesia related spinal injury can be a major issue in elevating back pain. Several evidences have established this process as a significant contributor of back pain; though contradictions are also present. This study aims to focus on the consequences of back pain associated with the effects of spinal anesthesia that have been received before several years. Methodology: 48 housewives are included in this study (20 subjects for vaginal delivery and 28 subjects for spinal anaesthesia induced cesarean section) based on convenient sampling method through assessing their socio-economic status and other attributing criteria. Pain detect tool was used to track back pain status and a semi structure questionnaire was used to explore other considerations. Results: Results have shown significant differences in pain responses after receiving spinal anesthesia (exposed group) than control group. Subjects have reflected significant differences in their pain perception scores. Conclusion: This study concludes that subjects have shown significant higher pain perception levels after receiving spinal anesthesia compared to general anesthesia. Decision of Cesarean section delivery should include patient's previous pain conditions and current need. Acute care in post surgical pain should be immediately addressed even after several months of the surgery.

Keywords: Back Pain, Spinal Anesthesia, Cesarean Section

Corresponding Author

Sarmishtha Chanda, Department of Physiology, Sister Nibedita Govt. General Degree College for Girls, Hastings House, Kolkata, West Bengal, India. Email: csarmishtha@yahoo.com
How to Cite this Article

Mukhopadhyay A, Bhattacharyya A, Chanda S, Syamal AK. Spinal anesthesia during cesarean section and persisting low back pain: a cross sectional study in West Bengal, India. Int J Med Res Rev. 2019;7(6):496-503.

Available From

https://ijmrr.medresearch.in/index.php/ijmrr/article/ view/1104
To Browse

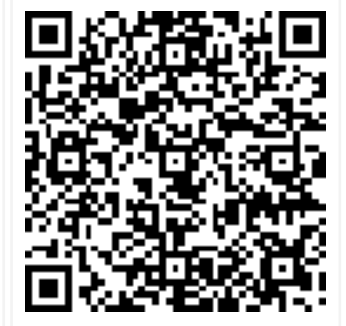

Manuscript Received 2019-11-04

Conflict of Interest No

Review Round 1
2019-11-14
Funding
Nil

Review Round 2
2019-11-20
Ethical Approval
Yes

Review Round 2 Yes
Review Round 3

Plagiarism X-checker $4 \%$
Accepted 2019-11-25

Note

() 2019 by Aditi Mukhopadhyay, Arpan Bhattacharyya, Sarmishtha Chanda, Alak Kumar Syamal and Published by Siddharth Health Research and Social Welfare Society. This is an Open Access article licensed under a Creative Commons Attribution 4.0 International License https://creativecommons.org/licenses/by/4.0/ unported [CC BY 4.0]. 


\section{Introduction}

Back pain is a very common and burdening health issue among the housewives of India.In other words, it can be called as a disorder that includes multiple etiologies. Various risk factors like stress, anxiety, depression, higher BMI, low bone mineral density were shown to be the attributing factorsfor persisting back pain. Occupational risk factors like manual handling of materials beyond recommended weight limit and lifting index, high duration of physical work, inappropriate postures, bending and twisting beyond the acceptable range can have an impact in the pathogenesis of back pain. Similarly, previous history of traumatic injury at the back can also aid in the pain perception.

According to some of the statistics, the prevalence of back pain among the Indian housewives was found to be $83 \%$ in the rural areas of Kanpur [1]. Around $42 \%$ women are found to be affected in this disorder in Puducherry. Most importantly, housewives were the worst sufferers of back pain and thus disability had snatched their quality of life [2].

Another study conducted in West Bengal has reflected that, prevalence of low back pain among rural housewives is $30 \%$ and the yearly prevalence of low back pain was $40 \%$ among them [3]. Such literatures are indicating the immediate need to sort out the issue with evidence-based practices and person-centric interventions.

Authors have reported that around $40.9 \%$ of the childbirths are taking place through Cesarean section (C- section) at private hospitals and around $11.9 \%$ are taking place in the government funded hospitals [4]. In this regard, several studies have shown the drawbacks of C-section delivery related epidural or spinal anesthesia. Women, who undergo this type of anaesthesia, are more prone to experience back pain in later life [5]. However, some evidences have contradicted this idea.

After giving the spinal or epidural anesthesia, patients began to report about the consequences of back pain even 6 months after surgery. Evidences have supported that; post-surgical persistent low back pain were common among the patients with cesarean section delivery [6]. Thus, the scenario of India regardingpost surgical back pain issue after cesarean section delivery has raised the need to confirm about its attribution.
Various evidences were reporting about the post surgical back pain for the spinal and epidural anesthesia. A study in Germany has reported that, post surgical back pain or PBP after the spinal anesthesia is very much associated with the history of pre-existing back pain among the patients who received the spinal or epidural anesthesia for the surgeries; but new occurrences of back pain after the anesthesia procedure is a very rare event [7]. An RCT conducted in Iran has reported that, spinal and epidural anesthesia could be a probable factor which is effective to develop a post surgical back pain among patients compared to the patients who received general anesthesia [8].

A case study reported in Washington, has demonstrated that spinal or epidural anesthesia can be a risk factor for developing back pain after 3 weeks of epidural catheter removal, which possibly occurs through the development of a vertebral osteomyelitis [9]. Moreover, a Danish study has reported that incidence of low back pain occurs in 2$25 \%$ after spinal anesthesia and epidural catheterization procedure [10]. Even the fear of back pain causes refusal of spinal anesthesia in about $13.4 \%$ cases during surgeries [11].

In contrast to the above, some of the evidences proved that, spinal anesthesia is not an effective trigger of post surgical chronic back pain. A study of Sweden has reported that, persistent post surgical back pain was not associated with spinal or epidural anesthesia but was associated with cesarean section [12]. An RCT conducted in Karachi, Pakistan has demonstrated that, there were no significant association exists between the epidural anesthesia and persistent postsurgical back pain [13]. Another study performed in Iran has shown that, there was no significant postsurgical pain reported after spinal and epidural anesthesia procedure in Cesarean section delivery [14]. These controversies have encouraged the curiosity to find out the actual scenario in West Bengal, which is perhaps never been addressed.

\section{Methodology}

Settings: The study has undertaken survey methods that are based on community settings. Housewives from different communities have been approached to take part in this study.

Duration and type of study: This is a retrospective study and was conducted from January 2018-July 2018. 
Sampling methods: Convenient sampling method was undertaken to select the study participants $(n=48)$. The study subjects include housewives belonging to middle socio-economic status from different parts of West Bengal, India with the age group considering 30-60 years. At first, they were approached verbally to take part in this study.

After their approval in participation, detailed study method and purpose of this study was explained to them. After that, women who have shown interests in participation have been evaluated further through inclusion and exclusion criteria.

Inclusion and exclusion criteria: The inclusion criteria were such so that, every patient had a consequence of back pain and were involved with the household job for at least 5 years. The subjects, who reported fever within 7 days of the interview process, were excluded from this study.

Data collection procedure: Subjects were interviewed through a semi-structured questionnaire basis, to explore the demographic data. Interview questionnaires were included the subjective and objective assessments of self-reported back pain. The subjective part was assessed through the 10point VAS scale. The objective part was determined through the Pain Detect tool [15]. Also, the retrospective histories of the childbirth histories (csection or vaginal delivery) and back pain were noted.

Data analysis: Descriptive and inferential statistics were done to satisfy the research question. Normality tests were done to explore the distribution pattern of the scores. Comparison tests were done between exposed group and their age matched controls. Socio-economic status was fixed as the baseline controller. 2-tail z-testand Pearson correlations were done to assess the significance levels of comparisons.

Ethical consideration \& permission: Informed consents were taken from the participants. This study was supported by the Institutional Ethical Committee Board. As this study does not include any invasive nature of interventions, thus, it can be said that ethical concept of beneficence and nonmalfeasance have been maintained properly.

Research question and hypothesis: Is spinal anesthesia during C-section delivery associated with the persistent post-surgical back pain among the housewives?
HO: Spinal anesthesia during C-section delivery is not significantly associated with the persistent postsurgical back pain among housewives $(P>0.05)$.

HA: Spinal anesthesia during C-section delivery is significantly associated with the persistent postsurgical back pain among the housewives $(P<0.05)$.

\section{Results}

The results were demonstrated as both as descriptive and inferential statistics. The descriptive statistics, which were used to compute the statistical test of comparisons, were represented in Table 1.

\section{Table-1: Descriptive statistics}

\begin{tabular}{|l|l|}
\hline \multicolumn{1}{|c|}{ Variable } & \multicolumn{1}{c|}{ Mean \pm SD } \\
\hline Age & $46.6 \pm 7.4$ \\
\hline VAS score & $5.06 \pm 2.93$ \\
\hline Pain Score & $11.55 \pm 5.93$ \\
\hline
\end{tabular}

The data determined from the study participants were assessed to explore whether they follow the normal distribution or not. The data which was nonnormal in its distribution was appropriately transformed through the transformation statistics. The following table shows the results of the normality tests (Table 2).

Table-2: Normality test statistics

\begin{tabular}{|l|l|l|}
\hline \multicolumn{1}{|c|}{ Variables } & \multicolumn{1}{|c|}{ K-S statistic } & \multicolumn{1}{c|}{ P value } \\
\hline Age & 0.102 & 0.2 \\
\hline VAS score & 0.167 & 0.003 \\
\hline Pain Score & 0.119 & 0.115 \\
\hline Corrected VAS score & 0.112 & 0.2 \\
\hline
\end{tabular}

The Kolmogorov-Smirnov or K-S test was performed to check the normal distribution of the data. All of the variables were shown to be normally distributed except the VAS scores. So, the VAS scores were appropriately transformed through data transformation statistics. These results indicate that the study in non-biased and reliable. The KMO and Bartlett's test was performed the check about the sampling adequacy, and the results of this test were shown below (Table 3 ).

Table 3: KMO and Bartlett's test.

\begin{tabular}{|l|l|l|}
\hline \multicolumn{2}{|c|}{ KMO and Bartlett's Test } \\
\hline Kaiser-Meyer-Olkin Measure of Sampling Adequacy. & 0.540 \\
\hline Bartlett's Test of Sphericity & Approx. Chi-Square & 40.825 \\
\cline { 2 - 3 } & df & 6 \\
\cline { 2 - 3 } & Sig. & 0.000 \\
\hline
\end{tabular}

The results of table 3 indicates that the sampling was adequate to describe the study model. 


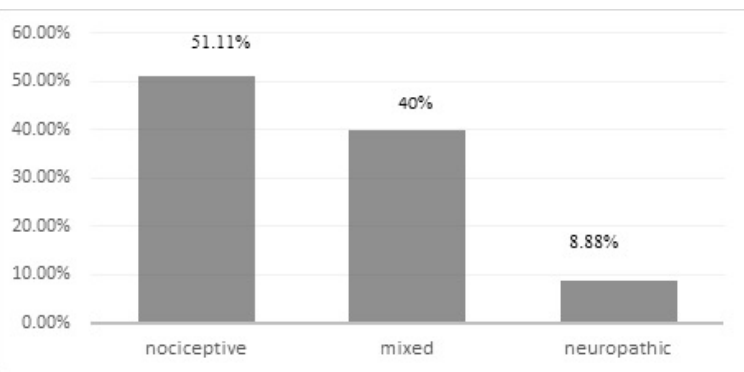

Fig-1: Objective categorization of pain through the responses from the subjects $(n=45)$.

Figure 1 states that, the nociceptive component of pain is predominant in this study, according to the Pain Detect Tool inference, with respect to other groups.

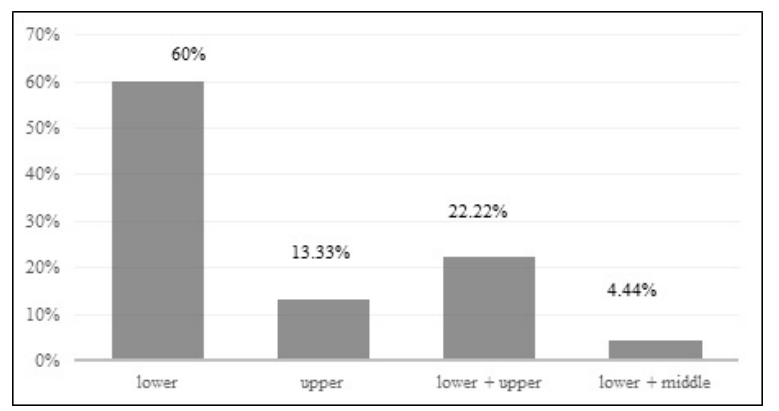

Fig-2: represents the locations of the back pain reported by the subjects $(n=48)$.

According to the figure 2, low back pain predominant in this study population. Also, some subjects have reported low back pain with spreading nature through the vertebral column.

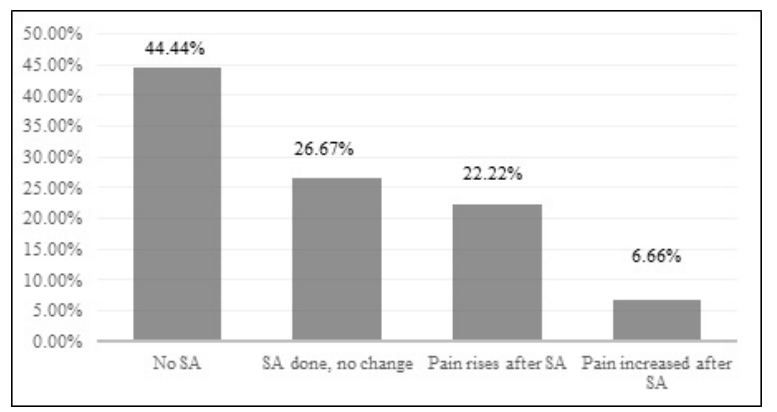

Fig-3: Describes the reported status of Spinal Anesthesia, $n=48$.

Figure 3 denotes that patients, about $26.67 \%$ of subjects have undergone spinal anesthesia with no change in pain perception than it was before. $22.22 \%$ reported that, back pain had rose after SA procedure and persisted for long years (beyond 1 year or more).
Also, $6.66 \%$ of subjects were reported to be higher in pain perception than before, after receiving spinal anesthesia procedure. $44.44 \%$ participants have received neither spinal anesthesia, nor cesarean section delivery at the time of childbirth; rather have undergonevaginal delivery or normal delivery.

Subjects were distributed into 2 major groups referred to control and exposed. Control group participants $(n=20)$ were undergone vaginal delivery and have not received any spinal anesthesia in their previous clinical history. The exposed group participants $(n=28)$ have received spinal anesthesia followed by cesarean section delivery during childbirth. The pain scores between the groups have been compared to explore the status of their pain status.

Table-4: Shows the t-test results between two groups of interest (comparison of pain scores).

\begin{tabular}{|l|l|l|l|l|l|}
\hline \multicolumn{1}{|c|}{ Groups } & \multicolumn{1}{|c|}{ SA status } & N & Mean & t-score & P (2-tailed) \\
\hline Control & 0 & 20 & 8.05 & -4.505 & 0.000 \\
\hline Exposed & 1 & 28 & 14.64 & & \\
\hline
\end{tabular}

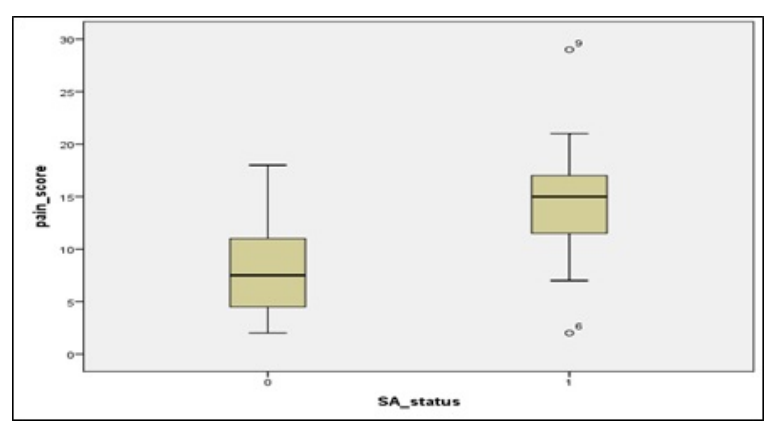

Fig-4: Demonstrates the significant mean differences in the pain score of the individuals $(n=48)$.

Table-5: Demonstrates the t-test results between two groups of interest (VAS core comparison).

\begin{tabular}{|l|l|l|l|l|l|}
\hline \multicolumn{1}{|c|}{ Groups } & SA status & $\mathbf{N}$ & Mean & t-score & P (2-tailed) \\
\hline Control & 0 & 20 & 3.95 & -2.157 & 0.010 \\
\cline { 1 - 4 } Exposed & 1 & 28 & 6.11 & & \\
\hline
\end{tabular}

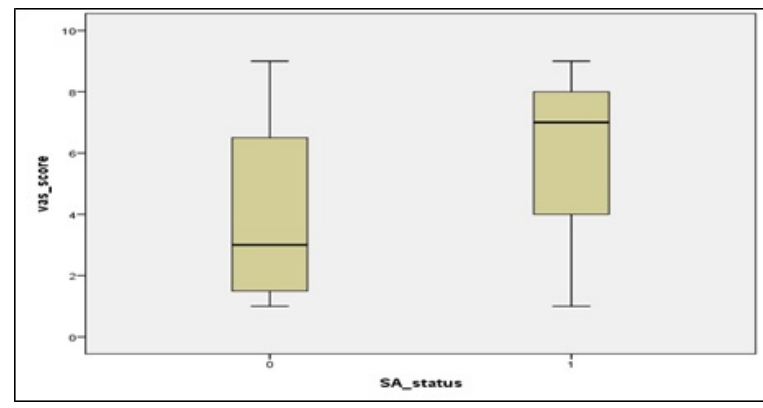


Fig-6: Demonstrates the significant mean differences of VAS scores between two groups $(n=48)$.

Pearson's correlation coefficients were computed to explore the relationships between the variables. The results of correlations were demonstrated in Table 6.

Table-6: Correlation status.

\begin{tabular}{|l|l|l|}
\hline \multicolumn{1}{|c|}{ Variables } & Correlation coefficient( $r)$ & P value \\
\hline Pain score and VAS score & 0.737 & 0.000 \\
\hline Pain score and spinal anesthesia & 0.373 & 0.012 \\
\hline Spinal anesthesia and VAS score & 0.232 & 0.125 \\
\hline
\end{tabular}

Significant correlations were found between the pain scores and the VAS scores of the subjects, $p=0.000$. Also, significant correlations were found between the pain scores and the status of the spinal anesthesia $(p=0.012)$. But VAS scores found to be non-significantly correlated with the status of spinal anesthesia $(p=0.125)$.

\section{Discussion}

This study investigated the incidences and association of persistent post surgical back pain with spinal anesthesia. From the results, it can be concluded that, majority of the subjects have received spinal anesthesia during their $\mathrm{C}$ - section delivery. Only $6.66 \%$ subjects reported that, they had previous histories of back pain, which were aggravated after the delivery and the pain persists till the interview period (beyond several years). New occurrences of back pain after surgery (persisted till the interview period; several years) were reported to be among the $22.22 \%$ subjects. These results were slightly contradicted by the study, where it was established that, new occurrences of the incidences of persisting post surgical back pain were a rare event; but the previous history of back pain is associated with Spinal anesthesia [7].

Pain scores between the groups differed significantly. Significant mean differences between the pain scores of control group and exposed group have been observed $(p=0.000)$. Thus, it can be said that, spinal anesthesia during cesarean section delivery may have attributed to their pain progression status. Furthermore, significant mean differences have been observed between two groups regarding pain perception status. VAS scores of the two groups have differed significantly $(p=0.010)$. Therefore, it can be said that, spinal anesthesia during cesarean section delivery may have attributed to their pain perception status.
Spinal anesthesia is observed to be correlated to some degree of pain score in a significant way. This result supports the idea of multifaceted cause of pain. In contrast to that, VAS scores have not been significantly correlatedwith the application of spinal anesthesia. Thus, it can be said that, pain perception of the individual depends on the pain score as well as other co morbid conditions present among the individuals.

Thus, Spinal Anesthesia can increase the risk of the neuropathic pain occurrences but the perception of the severity of pain completely lies on the other factors of the subjects; though pain perception status of the subjects in the exposed groups significantly differed from the control group. In this context, it should be mentioned that, several factors like lifestyle stress (elevated cortisol levels of individuals attribute to the elevated pain perception levels [16], anxiety (pain and anxiety acts as comorbid conditions and deteriorates the quality of life among the individuals [17]), depression (a remitted depressive or anxiety disorder showed more disabling and severely limiting pain $(O R=$ 3.53; $\mathrm{P}=0.001$ ) as compared to controls [18] etc can modulate the pain perception level of an individual. The results of this study contradicted the result of a Danish study, where it was concluded that, spinal anesthesia with 29-gauge needle could be a better alternative for the general anesthesia procedure before any surgery [10].

This study has some limitations that it doesn't include the separate data for the duration of the surgery or the doses of the anesthetic medicines. However, studies are there which also demonstrated correlation between epidural labour analgesia and chronic low back pain. According to one study, women who received cesarean delivery with epidural anesthesia were found to have higher risk of low back pain than women undergone vaginal delivery [19]. Pregnancy related low back pain could persist for as long as whole life from immediately after parturition. Low back pain could present as either pelvic girdle pain or between the posterior iliac crest and gluteal fold or as a persisting lumber pain over and around the lumbar spine [20].

Some authors have conducted study to evaluate the incidence of low back pain in women receiving epidural or spinal cartheterization during childbirth and concluded as positive correlation between spinal or epidural catheterization and persisting low back pain [21]. 
Studies are needed to conclude that, whether the patients of previous history of neuropathic pain are eligible to receive a spinal or epidural anesthesia before the cesarean section delivery or not. However, the risks of general anesthesia procedure are vast during surgery, which can be easily surpassed with spinal or epidural anesthesia. Consequences like nausea, headache, vomiting and increased risk of mortality are associated with the general anesthesia. Local (spinal or epidural) anesthesia is not associated with higher bleeding, depression, higher dehydration and higher nausea or vomiting tendencies. Despite having some consequences like post surgical persistent back pain and post dural puncture headache or PDPHA spinal anesthesia tends to be a safer process to save more lives [6]. The process of giving anesthesia before the C-section delivery should be carefully handled and post-surgical treatment of back pain should be readily addressed so that the pain grade can't reach the chronic state. If it remains unaddressed, then the neurological damage of spinal cord can be enhanced, for which the consequences can be worse.

\section{Limitations}

This study has been conducted only in survey and questionnaire format and doesnot include any medical results directly obtained from laboratory related to pain. All responses have been taken verbally from the subjects to evaluate their painful experiences; as evaluation of pain perception status after different types of anesthesia among subjects was the primary focus. Thus, further studies are recommended for evaluating clinical characteristics of pain responses of participants to link their pain perceptions with biological conditions of their body.

\section{Conclusion}

In conclusion it can be said that spinal anesthesia procedure in cesarean section delivery can add back pain sufferings in women. A significantly high different in pain perception status among c-section delivery and vaginal delivery has been found that indicates the occurrence of various risks.

\section{What the study adds to the existing knowledge?}

This research has been projected to add values in managing pain consequences in post surgical setups.
Especially approaches in pain management after childbirth are expected to be changed through the findings. Healthcare professionals can use this evidence as a support in providing proper health literacy to their patients after childbirth to manage and report their back pain in their clinics. Thus, it can be said that early reporting of pain in this segment can enhance the rate of prognosis and can improve quality of life among women.

Based on these research outcomes, further studies can be planned. For instance, studies can be conducted with different pain controlling therapies that will be helpful in managing acute and chronic consequences of post surgical back pain. Both pharmacological and non-pharmacological treatments can be considered here for therapeutic modalities. Thus, this research can be used in establishing a framework for handling post surgical back pain consequences in new mothers and also can help professionals to apply the therapeutic models in other postsurgical setups; where spinal anesthesia is strongly required.

\section{Author's contribution}

Aditi Mukhopadhyay: Study design, manuscript preparation

Arpan Bhattacharyya: Statistical analysis

Alak Kumar Syamal: Study design.

Sarmishtha Chanda: Concept, study design, manuscript preparation.

\section{Acknowledgement}

Authors sincerely acknowledge the assistance of Chinsurah block administration and Hoogly Mohsin College administrative block to arrange this work successfully.

\section{Reference}

01. Gupta G, Nandini N. Prevalence of low back pain in non working rural housewives of Kanpur, India. Int J Occup Med Environ Health. $2015 ; 28(2) 313-320$.

doi: 10.13075/ijomeh.1896.00299 [Crossref]

02. Saya G, Ahdhi G, Subramanian R, Yamuna T. Prevalence of low back pain and its relation to quality of life and disability among women in rural area of Puducherry, India. Ind J Pain. 2016;30(2)111-115. doi: 10.4103/0970-5333.186467 [Crossref] 
03. Mitra K, Chatterji S, Nandy S, Nandi C, Banerjee S. Prevalence of Low Back Pain and Disability among the Non-working Adult Women in a Rural Community of Purba Barddhaman, West Bengal. J Med Sci Clinic Res. 2017;5(5)22693-22698. doi: $10.18535 / j m s c r / v 5 i 5.233$ [Crossref]

04. Surana M, Dongre A. Too much care? Private health care sector and surgical interventions during childbirth in India. IIMA Working Papers, WP. 2018;1-26.

Available at: https://web.iima.ac.in/assets/snippets/ workingpaperpdf/916097432018-11-01.pdf [Crossref]

05. Holder HG, Graves CL. Spinal Anesthesia-A Survey of Neurologic Complications. California medicine. 1955;82(6)426-429.

[Crossref]

06. Ghafari MH, Movafegh A, Zadeh NS. A comparison of incidence of the Postdural Puncture Headache and Low Back Pain in the cesarean section patients undergoing spinal ane sthesia and general anesthesia- a randomized clinical trial study. Res J Biol Sci. 2009;4(2)1879. [Crossref]

07. Schwabe K, Hopf HB. Persistent back pain after spinal anaesthesia in the non-obstetric settingincidence and predisposing factors. Brit J Anaesthes. 2001;86(4)535-539.

doi: $10.1093 / \mathrm{bja} / 86.4 .535$ [Crossref]

08. Joudi M, Fathi $M$, Amin Dalili SJ, Ardabili AM, Akhondi $M$, Izanloo $A$. The association of anesthetic method with developing back pain after lower extremity operations. Anesthesiol Pain Med. 2014;4(5)e18194.

doi: 10.5812/aapm.18194 [Crossref]

09. Pinczower GR, Gyorke A. Vertebral osteomyelitis as a cause of back pain after epidural anesthesia. Anesthesiol- J Am Soc Anesthesiol. $1996 ; 84(1) 215-217$.

doi: $10.1097 / 00000542-199601000-00024$ [Crossref]

10. Dahl JB, Schultz P, Anker-Moller E, Christensen $E F$, Staunstrup HG, Carlsson P. Spinal anaesth esia in young patients using a 29-gauge needletechnical considerations and an evaluation of postoperative complaints compared with general anaesthesia. Br J Anaesth. 1990;64(2)178-182. doi: $10.1093 / \mathrm{bja} / 64.2 .178$ [Crossref]
11. Rafique $M$, Taqi A. The Causes, prevention and management of post spinal backache- an overview. Anaesth Pain Intens Care. 2011;15(1)65-69.

[Crossref]

12. Mogren IM. Does caesarean section negatively influence the post-partum prognosis of low back pain and pelvic pain during pregnancy?. Europe Spine J. 2007;16(1)115-121.

doi: 10.1007/s00586-006-0098-8 [Crossref]

13. Abbasi S, Hamid M, Ahmed Z, Nawaz FH. Prevalence of low back pain experienced after delivery with and without epidural analgesia- A non-randomised prospective direct and telephonic survey. Ind J Anaesthes. $2014 ; 58(2) 143-148$. doi: $10.4103 / 0019-5049.130814$ [Crossref]

14. Lak M, Forozanmehr M, Dodange F. Spinal versus epidural anesthesia complications, outcomes and pain relieving capacity. Kawsar Med J. 2008;13(2)153-161.

[Crossref]

15. Freynhagen R, Baron R, Gockel U, Tölle TR. Pain DETECT- a new screening questionnaire to identify neuropathic components in patients with back pain. Curr Med Res Opinion. $2006 ; 22(10) 1911-1920$.

doi: $10.1185 / 030079906 \times 132488 \quad$ [Crossref]

16. Vachon-Presseau E, Roy M, Martel MO, Albouy G, Chen J, Budell L, Rainville P. Neural processing of sensory and emotionalcommunicative information associated with the perception of vicarious pain. Neuroimage. 2012;63(1)54-62.

doi: 10.1016/j.neuroimage.2012.06.030 [Crossref]

17. Castro M, Quarantini LC, Daltro C, Pires-Caldas M, Koenen KC, Kraychete DC, et al. Comorbid depression and anxiety symptoms in chronic pain patients and their impact on health-related quality of life. Arch Clinic Psych (São Paulo). $2011 ; 38(4) 126-129$.

doi: $10.1590 / S 0101-60832011000400002$ [Crossref]

18. The association of depression and anxiety with pain- a study from NESDA. PloS one. 2014;9(10)e106907. doi: 10. 1371/journal.pone.0106907 [Crossref] 
19. Chia YY, Yuan Lo, Chen YB, Liu CP, Huang WC, Wen $\mathrm{CH}$. Risk of Chronic Low Back Pain Among Parturients Who Undergo Cesarean Delivery with Neuraxial Anesthesia A Nationwide Population-Based Retrospective Cohort Study. Medicine. 2016;95(16)1-6.

doi: $10.1097 / M D .0000000000003468$ [Crossref]

20. Katonis $P$, Kampouroglou A, Aggelopoulos A, Kakavelakis K, Lykoudis,S, Makrigiannakis A, et al. Pregnancy - related low back pain. Hippokratia. 2011;15(3)205-210.

[Crossref]
21. Wang $\mathrm{CH}$, Cheng $\mathrm{KW}$, Neoh $\mathrm{CA}$, Tan $\mathrm{S}$, Jawan $\mathrm{B}$ Lee $\mathrm{JH}$. Comparison of the incidence of postpartum low back pain in natural childbirth and cesarean section with spinal anesthesia. Acta Anaesthesiologica Sin. 1994;32(4)243246.

[Crossref] 